\title{
The Chelyabinsk event
}

\author{
Jiří Borovička \\ Astronomical Institute of the Czech Academy of Sciences, Fričova 298, CZ-25165 Ondřejov, \\ Czech Republic \\ email: jiri.borovicka@asu.cas.cz
}

\begin{abstract}
On February 15, 2013, 3:20 UT, an asteroid of the size of about 19 meters and mass of 12,000 metric tons entered the Earth's atmosphere unexpectedly near the border of Kazakhstan and Russia. It was the largest confirmed Earth impactor since the Tunguska event in 1908. The body moved approximately westwards with a speed of $19 \mathrm{~km} \mathrm{~s}^{-1}$, on a trajectory inclined 18 degrees to the surface, creating a fireball of steadily increasing brightness. Eleven seconds after the first sightings, the fireball reached its maximum brightness. At that point, it was located less than $40 \mathrm{~km}$ south from Chelyabinsk, a Russian city of population more than one million, at an altitude of $30 \mathrm{~km}$. For people directly underneath, the fireball was 30 times brighter than the Sun. The cosmic body disrupted into fragments; the largest of them was visible for another five seconds before it disappeared at an altitude of $12.5 \mathrm{~km}$, when it was decelerated to $3 \mathrm{~km}$ $\mathrm{s}^{-1}$. Fifty six second later, that $\sim 600 \mathrm{~kg}$ fragment landed in Lake Chebarkul and created a $8 \mathrm{~m}$ wide hole in the ice. Small meteorites landed in an area $80 \mathrm{~km}$ long and several $\mathrm{km}$ wide and caused no damage. The meteorites were classified as LL ordinary chondrites and were interesting by the presence of two phases, light and dark. More material remained, however, in the atmosphere forming a dust trail up to $2 \mathrm{~km}$ wide and extending along the fireball trajectory from altitude 18 to $70 \mathrm{~km}$. The dust then circled the Earth within few days and formed a ring around the northern hemisphere. In Chelyabinsk and its surroundings a very strong blast wave arrived $90-150 \mathrm{~s}$ after the fireball passage (depending on location). The wave was produced by the supersonic flight of the body and broke $\sim 10 \%$ of windows in Chelyabinsk $(\sim 40 \%$ of buildings were affected). More than 1600 people were injured, mostly from broken glass. The whole event was well documented by video cameras, seismic and infrasonic records, and satellite observations. The total energy was $500 \mathrm{kT}$ TNT $\left(2 \times 10^{15} \mathrm{~J}\right)$.
\end{abstract}

Keywords. Meteors, Meteoroids, Asteroids

\section{Introduction}

It is now widely acknowledged that impacts of cosmic bodies (asteroids and comets) played important role in the history of Earth's life. The most significant impacts, of multikilometer bodies, occur only on geological timescales. The largest impact in modern history was the Tunguska event in Siberia on June 30, 1908 (Vasilyev 1998). The asteroid of a size of about 50 meters exploded $5-10 \mathrm{~km}$ above the surface and its radiation ignited the forest beneath. The blast wave arrived somewhat later, ceased the fire but flattened the forest on an area of $2150 \mathrm{~km}^{2}$. The total energy of the event was estimated about $15 \mathrm{MT}$ TNT $\left(1 \mathrm{kT}\right.$ TNT $\left.=4.184 \times 10^{12} \mathrm{~J}\right)$. For comparison, the larges thermonuclear test ever conducted (in the USSR in 1961) had an energy of 50 MT TNT, while the Hiroshima bomb had only $15 \mathrm{kT}$ TNT. More recently detected impacts, such as those near Marshall Islands in 1994 (McCord et al. 1995) and near Sulawesi, Indonesia, in 2009 (Silber et al. 2011) had an energy of the order of tens of kilotons. There was, nevertheless, one unconfirmed event of the energy of 1.5 MT TNT over Indian Ocean in 1963 (Silber et al. 2009).

On February 15, 2013, the citizens of the Russian city Chelyabinsk of more than one 
Table 1. Energy estimates from various types of data.

\begin{tabular}{lcc}
\hline Method & Energy (kt TNT) & Reference \\
\hline Seismic & 430 & Brown et al. $(2013)$ \\
Infrasound & 600 & $"$ \\
US government sensors & 530 & $"$ \\
Video-derived light curve & $>470$ & Popova et al. $(2013)$ \\
Infrasound & 570 & . \\
\hline
\end{tabular}

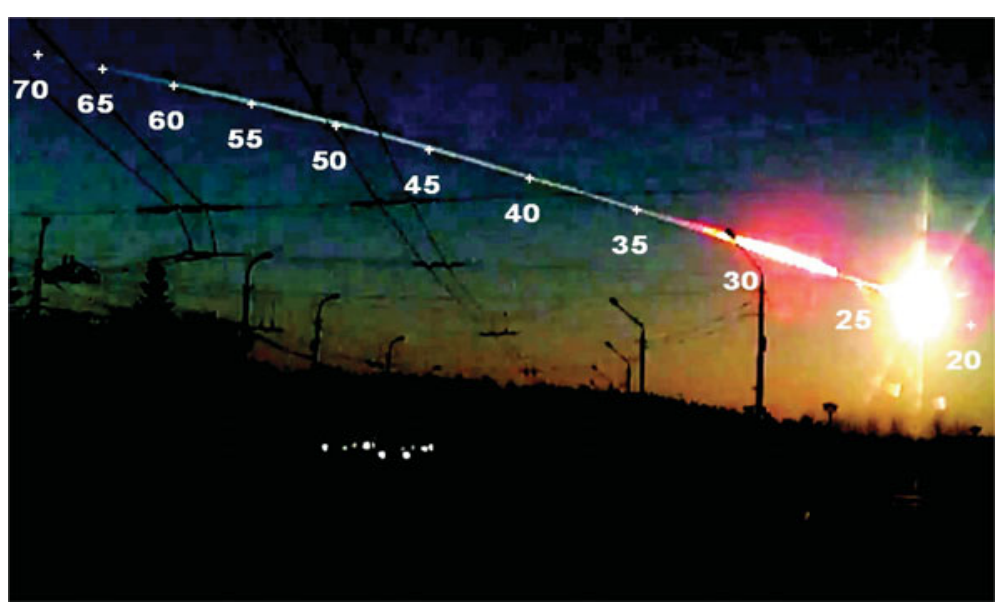

Figure 1. The bolide and fresh dust trail as seen from north. Frame from video taken by A. Ivanov in Kamensk-Uralskyi. The numbers are altitudes in $\mathrm{km}$ above ground.

million of inhabitants and the wide surroundings were surprised by bright bolide on the clear morning sky (Fig. 1). Although two small impactors had been discovered (by chance) in space the day before their impacts (Jenniskens et al. 2009; Chesley et al. 2015), the much larger Chelyabinsk impact came as a surprise. In fact, there was no chance to discover the impactor since it came from the direction close to the Sun (Borovička et al. 2013). The atmospheric entry was well documented and we can reconstruct in much more detail what happened than in previous cases. More than 400 casual video records of the bolide, from dashboard cameras in cars, security cameras, and traffic cameras, were posted on the Internet (Borovička et al. 2015). Additional hundreds of videos showed the bolide light, dust trail in the atmosphere, or the damage caused by the blast wave. The arrival of the blast wave and secondary sonic booms were recorded in the sound tracks of the videos. Further data came from seismic records and infrasonic records from around the world. The dust trail was imaged from the orbit by meteorological satellites (Proud 2013; Miller et al. 2013), see Fig. 2. The US Government sensors also recorded the event. Finally, the recovered meteorites were analyzed.

\section{The results}

The results of the analyses of various data have been already published in a number of papers, although some more detailed studies are still underway. The estimates of the total energy of the whole event obtained by various methods by different authors are summarized in Table 1. There is good agreement of $500 \pm 100 \mathrm{kT}$ TNT. The bolide trajectory was computed from calibrated videos by Borovička et al. (2013) and Popova et al. (2013) and are also in good agreement. Other computations found in the literature 

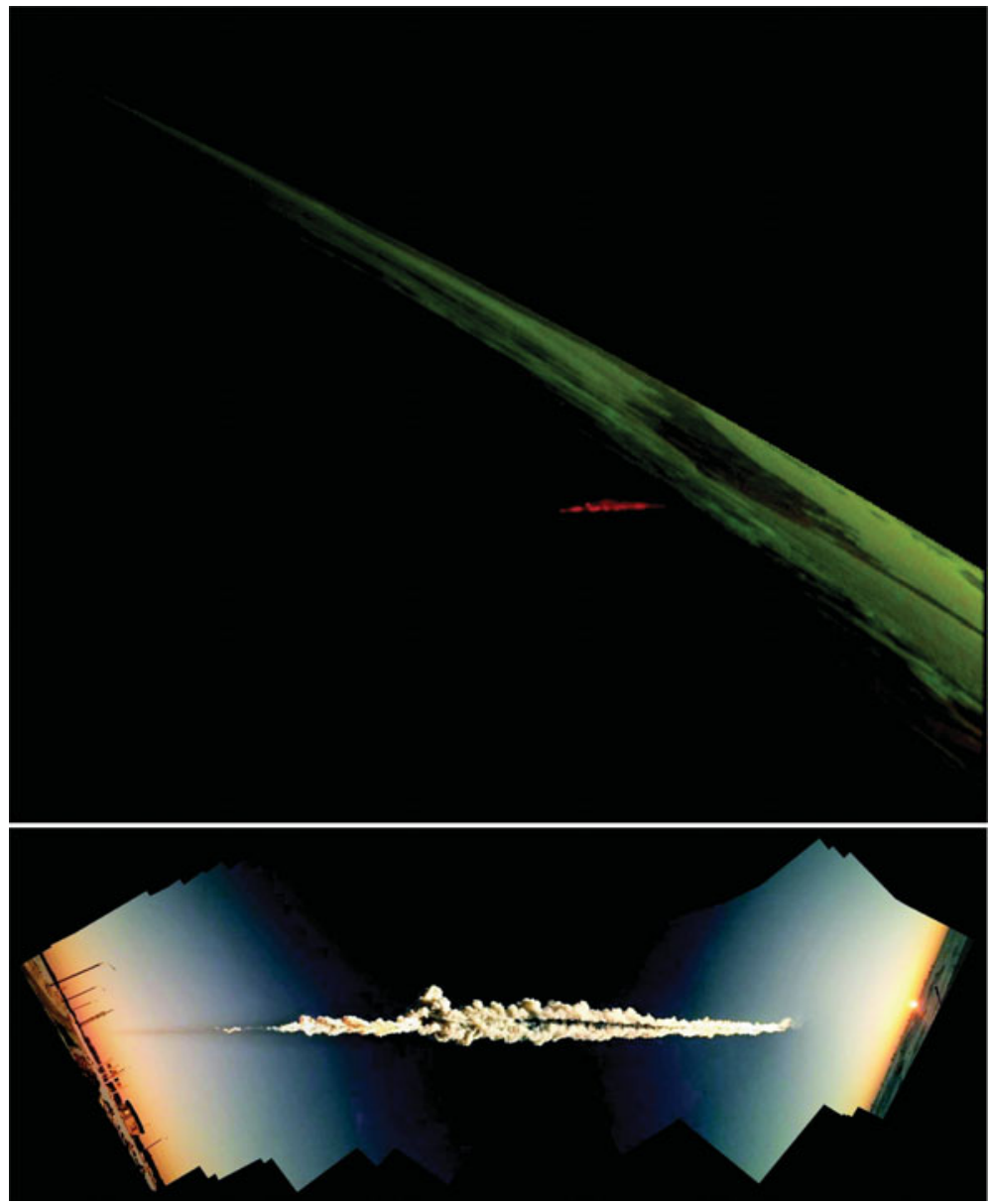

Figure 2. Dust trail from space and from ground. The upper image was taken by MSG2 satellite from geostationary orbit. Combination of visible and infrared channel. Courtesy Eumetsat and CHMI (Z. Charvát). The lower image was composed by L. Shrbený from video taken by A. Vazhenin in Borisovka, where the trail was seen directly overhead and was illuminated by the rising Sun (on the right).

are less reliable. Borovička et al. (2013) gave the observed height span $95.1-12.6 \mathrm{~km}$, the slope of the trajectory ( $272 \mathrm{~km}$ long) relatively to the horizontal $18.5^{\circ}$ at the beginning and $17^{\circ}$ at the end (the slope changes primarily due to Earth's curvature, although the trajectory itself was also not straight), the initial velocity $19.03 \pm 0.13 \mathrm{~km} \mathrm{~s}^{-1}$, terminal velocity $3.2 \mathrm{~km} \mathrm{~s}^{-1}$, and bolide duration 17 seconds.

Combining the known trajectory with the arrival times of the blast wave at various sites, it was proven that the blast wave causing damage was cylindrical not spherical. The wave originated at various heights between $25-35 \mathrm{~km}$, not in a single point (Brown et al. 2013). It was therefore produced by the supersonic flight of the fragmenting asteroid. Secondary, weaker shocks after the main arrival were spherical waves from various fragmentation points. The region of damage extended perpendicularly from the part of the trajectory, where most energy was deposited (Popova et al. 2013). According to Popova et al. (2013), windows of 7,230 buildings were affected. Brown et al. (2013) examined more than 5000 windows in the city of Chelyabinsk and found that nearly $10 \%$ of them broke due to initial shock and $40 \%$ of buildings were affected. The window glass velocity 


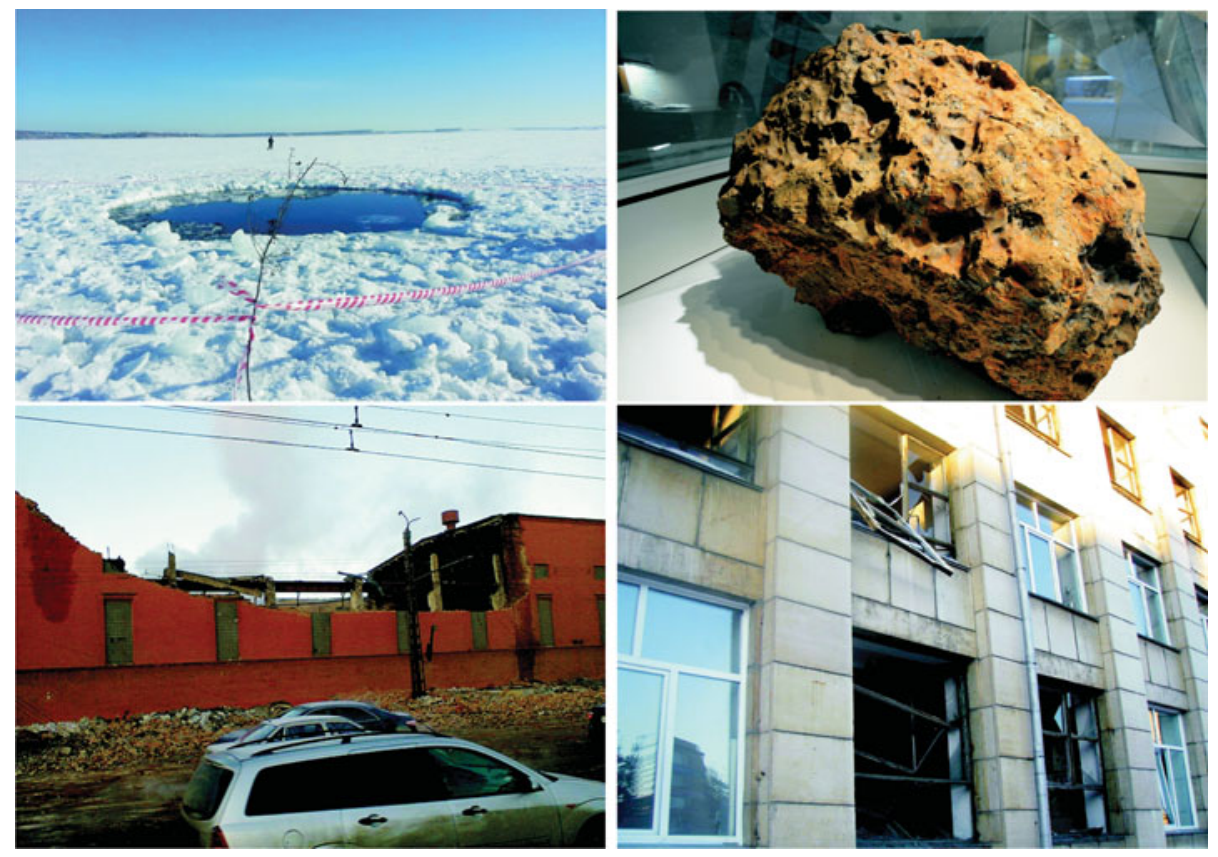

Figure 3. The hole in the ice of Lake Chebarkul caused by the impact of the largest fragment, the largest fragment displayed in Chelyabinsk museum, the collapsed roof and wall of the Chelyabinsk zinc plant, and windows in Chelyabinsk destroyed by the blast wave.

was measured to be $7-9 \mathrm{~m} \mathrm{~s}^{-1}$. The roof one building collapsed (Fig. 3). The pressure was a few percent of atmospheric pressure. Popova et al. (2013) reported that 1,613 people asked for medical assistance at hospitals, 112 people were hospitalized, 2 in serious condition. There were, fortunately, no fatalities. Most injuries were from broken glass. Other inconveniences reported by the people were heat, sunburn, painful eyes, temporal deafness, and stress. No significant damage or injuries was caused by falling meteorites.

From the known energy and velocity, the mass of the impacting asteroid was found to be $12,000 \mathrm{~kg}$. Assuming that the density of the meteorites $\left(3300 \mathrm{~kg} \mathrm{~m}^{-3}\right)$ was valid for the whole body gives the asteroid equivalent diameter $19 \pm 2 \mathrm{~m}$. The asteroid severely fragmented in the atmosphere. The fragmentation was modeled by Borovička et al. (2013) using the observed light curve (total bolide brightness as a function of time), times of arrivals of secondary sonic booms, and deceleration toward the end of trajectory. Fresh dust trail images were also considered. It was found that intensive dust release (from near-surface) started at height about $70 \mathrm{~km}$. The first fragmentation occurred at $45 \mathrm{~km}$, where $1 \%$ of mass was lost. Large scale disruption with $95 \%$ mass loss occurred at heights $39-30 \mathrm{~km}$. By $29 \mathrm{~km}$ the asteroid was fragmented into $10-20$ boulders of sizes $1-3$ $\mathrm{m}$. These boulders then broke again at $26-22 \mathrm{~km}$. Only one large $(\sim 0.7 \mathrm{~m})$ fragment survived and landed in Lake Chebarkul (Fig. 3), from where it was lifted up 8 months later (Popova et al. 2013).

We can compare the dynamic pressure acting at the fragmentations $\left(p=\rho v^{2}\right.$, where $\rho$ is atmospheric density and $v$ is velocity) with the typical tensile strength of meteorites, which is about $50 \mathrm{MPa}$ (Popova et al. 2011). The first fragmentation occurred at 0.5 $\mathrm{MPa}$, severe destruction at $1-5 \mathrm{MPa}$, and secondary fragmentation of boulders at $10-$ $18 \mathrm{MPa}$. The maximum pressure encountered by the largest surviving fragment was 15 $\mathrm{MPa}$. The bulk strength of few megapascals is obviously much lower than the strength 


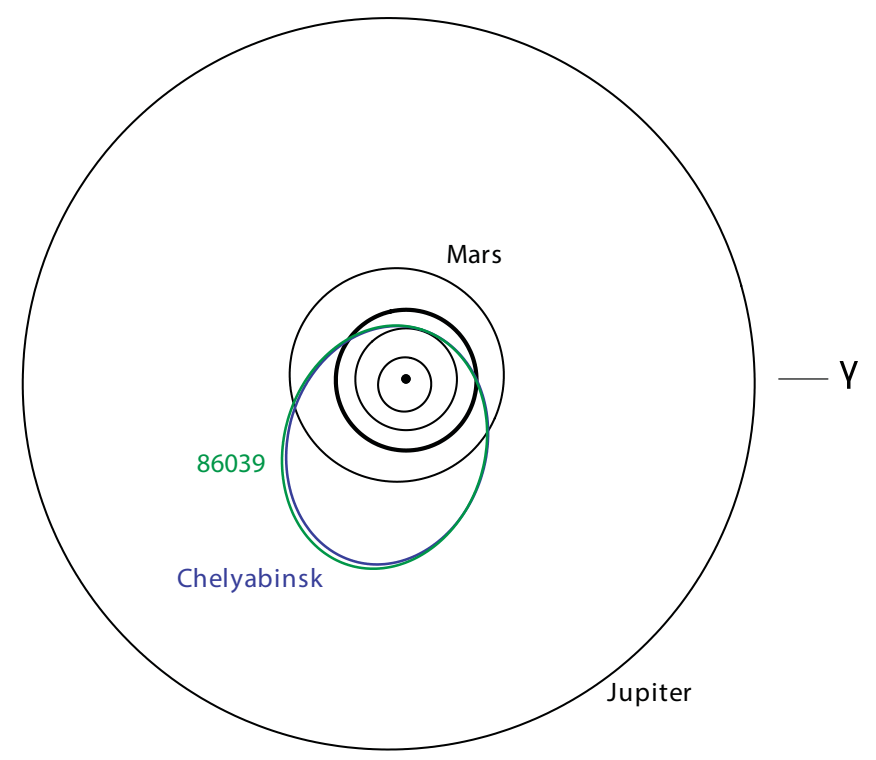

Figure 4. Orbits of Chelyabinsk and asteroid 86039 (1999 NC43).

of meteoritic material but is similar to other meteoroids (Popova et al. 2011). The low strength was probably caused by internal cracks from previous collisions in interplanetary space. The parts with strength larger than $10 \mathrm{MPa}$ represented only few percent of the body.

At least 1923 meteorites recovered in a strewn field $80 \mathrm{~km}$ long and $7 \mathrm{~km}$ wide (Badyukov et al. 2014). Most of them very small (mass $\sim 1 \mathrm{~g}$ ). More than $625 \mathrm{~kg}$ of meteoritic material was found in Lake Chebarkul (Popova et al. 2014). A $24.3 \mathrm{~kg}$ fragment was found near Travniki following the prediction of Borovička et al. (2013). Other cataloged meteorites have masses $0.04 \mathrm{~g}-3.4 \mathrm{~kg}$ and total mass $94 \mathrm{~kg}$. Total fallen mass was estimated to $4,000-10,000 \mathrm{~kg}$. i.e. only $0.03-0.08 \%$ of the initial mass (Popova et al. 2014).

The meteorites were classified as LL type ordinary chondrite breccia (Kohout et al. 2014). LL is a common type of meteorite (represents $9 \%$ of all falls). However, two lithologies (light and dark) are present, together with impact melt. All three phases have identical composition. The dark lithology was produced by shock-darkening (Kohout et al. 2014; Reddy et al. 2014; Richter et al. 2015). Its reflectance spectrum can mimic carbonaceous material. The cosmic ray exposure age was measured to be $1.2 \mathrm{Myr}$, one of the lowest among LL chondrites (Popova et al. 2013; Povinec et al. 2015).

The dust trail left in the atmosphere was mostly formed by micron sized dust. It represents unablated residuals of tiny fragments. Total mass of the dust may be $25 \%$ of the initial mass (Popova et al. 2013). Within few days after the event, the dust circled the globe forming a optically thin dust ring around the northern hemisphere (Gorkavyi et al. 2013). The dust remained detectable in the atmosphere for three months (Rieger et al. 2014).

The pre-impact orbit of the asteroid was found to be very similar to that of asteroid 86039 (1999 NC43) with diameter of about $2 \mathrm{~km}$ (Borovička et al. 2013). Although there is only $\sim 1: 10,000$ chance that the proximity of Chelyabinsk orbit (Fig. 2) to an asteroid of this size is due purely to chance, spectral comparison did not confirm genetic relation 
(Reddy et al. 2015). Detailed analysis of the reflectance spectrum of 1999 NC43 showed that it is of type $\mathrm{L}$ rather than LL.

The statistics of large bolides (Brown et al. 2013) and asteroid discoveries (Harris \& D'Abramo 2015) now agree better than in the past and suggest that the impacts of Chelyabinsk size occur globally once per $40 \pm 20$ years on average.

\section{Summary}

The Chelyabinsk event was the first asteroid disaster in (at least modern) history. The damage was from the blast wave. If the body were stronger and penetrated deeper intact, the blast wave would be more damaging. In any case Chelyabinsk demonstrated that $20-\mathrm{m}$ asteroids are dangerous and that asteroids of this size are more numerous than was thought several years ago. The new survey telescopes like ATLAS (Tonry 2011) and LSST (Jones et al. 2009) can provide advance warning if the impactor comes from the night side. Day side can be covered only from space.

\section{Acknowledgements}

This work was supported by project P209/11/1382 from the Czech Science Foundation (GAČR). The institutional project was RVO:67985815.

\section{References}

Badyukov, D. D., Dudorov, A. E. \& Khaibrakhmanov, S. A. 2014. Vestnik Chelyab. Gosudar. Univ., 1/2014, Fizika, Vyp. 19, p. 40 (in Russian)

Borovička, J., Spurný, P., Brown, P. et al. 2013. Nature, 503, 235

Borovička, J., Shrbený, L., Kalenda, P. et al. 2015. Astron. Astrophys., in press, doi: $10.1051 / 0004-6361 / 201526680$

Brown, P. G., Assink, J. D., Astiz, L. et al. 2013. Nature, 503, 238

Chesley, S. R., Farnocchia, D., Brown, P.,G., \& Chodas, P.,W. 2015. In Aerospace Conference, 2015 IEEE , 8 pp., 7-14 March 2015, doi: 10.1109/AERO.2015.7119148

Gorkavyi, N., Rault, D. F., Newman, P. A. et al. 2013. Geophys. Res. Lett. 40, 4728

Harris, A. W. \& D'Abramo, G. 2015. Icarus, 257, 302

Jenniskens, P., Shaddad, M. H., Numan, D. et al. 2009. Nature, 458, 485

Jones, R. L., Chesley, S. R., Connolly, A. J., et al. 2009, Earth Moon and Planets, 105, 101

Kohout, T., Gritsevich, M., Grokhovsky, V. I. et al. 2014. Icarus, 228, 78

McCord, T. B., Morris, J., Persing, D. et al. 1995. J. Geophys. Res. 100 (E2), 3245.

Miller, S. D., Straka III, W. C. , Scott Bachmeier, A. et al. 2013. PNAS, 110, 18092

Popova, O., Borovička, J., Hartmann, W. K. et al. 2011. Meteorit. Plan. Sci., 46, 1525

Popova, O. P., Jenniskens, P., Emel'yanenko, V. et al. 2013. Science, 342, 1069

Popova, O. P., Jenniskens, P., \& Glazachev, D. O. 2014. In: Geofiz. effekty padeniya Chelyab. Meteorita (Moscow: IDG RAS), Dynam. Proc. Geospher. 5, 59 (In Russian)

Povinec, P. P., Laubenstein, M., Jull, A. J. T. et al. 2015. Meteorit. Plan. Sci., 50, 273

Proud, S. R. 2013. Geophys. Res. Lett. 40, 3351

Reddy, V., Sanchez, J. A., Bottke, W. F. et al. 2014. Icarus, 237, 116

Reddy, V., Vokrouhlický, D., Bottke, W. F. et al. 2015. Icarus, 252, 129

Richter, K., Abell, P., Agresti, D. et al. 2015. Meteorit. Plan. Sci., 50, 1790

Rieger, L. A., Bourassa, A. E., \& Degenstein, D. A. 2014. Atmos. Meas. Tech., 7, 777

Silber, E. A., ReVelle, D. O., Brown, P. G. \& Edwards, W. N. 2009. J. Geophys. Res., 114, E08006.

Silber, E. A., Le Pichon, A. \& Brown, P. G. 2011. Geophys. Res. Lett., 38, L12201.

Tonry, J. L. 2011. Publ. Astron. Soc. Pacific, 123, 58

Vasilyev, N. V. 1998. Plan. Space Sci., 46, 129. 